\title{
COMUNIDAD ÉTICA, SOCIEDAD CIVIL Y MERCADO ESBOZOS PARA UNA CRÍTICA A LA REVOLUCIÓN NEOLIBERAL A PARTIR DEL CONCEPTO KANTIANO DE COMUNIDAD ÉTICA
}

\author{
ETHICAL COMMUNITY, CIVIL SOCIETY AND MARKET \\ SKETCHES FOR A CRITIQUE OF THE NEOLIBERAL REVOLUTION \\ FROM THE KANTIAN CONCEPT OF ETHICAL COMMUNITY
}

Alessandro Caviglia*

Recepción: 18-Noviembre/2016

Aceptación: 12/Marzo/2017

\begin{abstract}
RESUMEN
El presente trabajo asume el concepto kantiano de comunidad ética como punto de partida crítico para construir una concepción de sociedad civil que pueda hacer frente a las pretensiones de un capitalismo desmensurado que se ha articulado a través de la forjación de un mercado global autorregulado. Para realizar el análisis se han tomado, como apoyo adicional, los trabajos clásicos en antropología económica, como los de Marcel Mauss y Marshal Sahlins y los trabajos de economía, sociología y economía desarrollados por Karl Polanyi, y se han reevaluado a través de los trabajos en filosofía política y filosofía social contemporánea.
\end{abstract}

\section{PALABRAS CLAVE}

Immanuel Kant, comunidad ética, neoliberalismo, Sociedad civil antropología económica.

\begin{abstract}
The present work takes on the Kantian concept of ethical community as a critical starting point to construct a conception of civil society that can cope with the pretensions of an exaggerated capitalism that has been articulated through the forging of a global self-regulated market. In order to carry out the analysis, classical works in economic anthropology, such as those of Marcel Mauss and Marshal Sahlins, together with Karl Polanyi's studies on economics, sociology and economics have been taken as additional support and re-evaluated through the perspective of contemporary works on political and social philosophy.
\end{abstract}

\section{KEY WORDS}

Immanuel Kant, ethics community, neoliberalism, civil society economic, anthropology.

Profesor de la Pontificia Universidad Católica del Perú: ascaviglia@yahoo.com 


\section{INTRODUCCIÓN}

Las sociedades contemporáneas se encuentran interconectadas y atravesadas por un conjunto de redes que constituyen lo que denominamos globalización. Una de las más penetrantes de dichas redes, y que levantan relaciones de dominación de una persona a otra es la conocida como red del mercado mundial. El mercado mundial autorregulado se ha extendido con ferocidad a lo largo del globo estableciendo relaciones sociales que traspasan las fronteras nacionales y producen gobernaciones transnacionalizadas. En esas circunstancias es necesario ganar diferentes puntos de vista críticos que permitan evaluar la situación global en las condiciones históricas presentes y sirvan para denunciar las afectaciones a la dignidad de las personas. En este sentido, las ideas de dignidad, de comunidad ética y de virtud desarrolladas por Kant nos ofrecen herramientas críticas importantes para la crítica social propia de una filosofía social de carácter normativo.

\section{La Idea de Comunidad Ética}

La idea de comunidad ética desarrollada por Kant en su Religión dentro de los límites de la mera razón puede ser tomada como punto de partida para elaborar un punto de vista crítico respecto de la sociedad. Esto permite articular una filosofía social de carácter normativo. El presente trabajo tiene como objetivo extraer algunos elementos básicos para comenzar a articular una filosofía crítica sobre la sociedad, a parir de la idea de la comunidad ética. Para ello incorporará algunas ideas centrales desarrolladas por Kant en su Doctrina de la virtud presente en la Metafísica de las costumbres, especialmente el concepto de deberes de virtud tanto para con uno mismo como para con los demás. A fin de realizar el tránsito de la comunidad ética a la sociedad se recurrirá a los trabajos de Karl Polanyi y los aportes de la filosofía política junto con los aportes de la antropología económica, de los cuales se extraerá material filosófico, sociológico, antropológico e histórico relevante.

La idea de comunidad ética brota del estudio sobre la eclesiología crítica que el filósofo de Köninsberg desarrolla en la tercera sección de su libro sobre religión, bajo el título de El triunfo del principio bueno sobre el malo y la fundación de un reino de Dios sobre la tierra. En él se expone que la lucha que el ser humano emprende contra el principio malo que lo habita tiene las siguientes características: a) se trata de una lucha permanente y b) las causas que mantienen al ser humano presa del mal no provienen solamente de su condición de ser aislado de los demás, sino que al interior de la misma convivencia social surgen fuerzas (bajo la forma de la envidia, la codicia, el ansia de dominar sobre los otros y las tendencias hostiles hacia los demás, entre otras) que arrastran a los individuos hacia el mal. Todas estas fuerzas y tendencias se hacen presentes tan pronto el individuo vive en sociedad. No requiere suponer que el individuo se encuentra hundido en el mal (es decir, corrompido completamente), sino que basta con verlo insertado en la vida social, lugar en el que los hombres se corrompen mutuamente en su disposición moral y se hacen malos unos frente a los otros. El dominio del principio bueno es posible solamente por medio de la construcción y la extensión de una sociedad en la cual los sujetos se comportan según leyes de virtud, sociedad que es erigida por mandatos que provienen de la moral, es decir, por un imperativo categórico. Así, la construcción de tal sociedad se hace tarea y deber por medio de la razón.

La razón misma ordena al género humano la construcción de dicha sociedad por medio de un mandato incondicional 
que exige formar una sociedad ética que liga a los hombres bajo leyes de virtud. Pero dicha comunidad es una sociedad civil ética o comunidad ética en tanto sus leyes son públicas, es decir, de conocimiento público y que rigen las relaciones entre los miembros de la comunidad. Se trata de una comunidad ética en contraposición de una comunidad civil de derecho o comunidad política. Pero esta comunidad ética puede muy bien existir en medio de una comunidad política e incluso estar formada por todos los miembros de la misma, pero en relación a la comunidad política tiene un principio de unión distinto, la virtud, además de una forma y una constitución distinta.

La comunidad civil de derecho se encuentra regida según leyes públicas de carácter vinculante, respecto de las cuales las autoridades legítimas tienen la facultad de coaccionar a quienes no las respeten. Además, dicha comunidad se encuentra contrapuesta al estado de naturaleza jurídica. La comunidad civil ética se encuentra regida por leyes de virtud, respecto de las cuales no existe poder externo al sujeto que tenga la facultad de coaccionar el incumplimiento de tales leyes. Además, la comunidad civil ética se encuentra contrapuesta al estado de naturaleza ético. Aquí, en esta comunidad ética, el hombre se da leyes a sí mismo, cada uno es su propio juez y no hay ninguna autoridad pública poseedora de poder que, según leyes, determine con fuerza de derecho lo que en las cosas que se presentan es deber de cada uno y lleve ese deber a ejercicio general.

Pero, a pesar de sus diferencias, la comunidad civil de derecho y la comunidad civil ética guardan ciertas relaciones entre sí. En las comunidades políticas existentes los ciudadanos se encuentran en estado de naturaleza ética entre sí y están autorizados a permanecer en él. Así, en el texto Para la paz perpetua Kant afirma que "El establecimiento de un Estado, por duro que suene, aún para un pueblo de demonios (con tal que tengan entendimiento) es dirimible" (Kant, 1999, P.333).

Sería, más bien, una contradicción el que la comunidad política forzara a los ciudadanos a entrar en una comunidad civil ética, puesto que esta última tiene implícita en su concepto la libertad respecto de toda coacción. La comunidad política puede desear que los ciudadanos se vinculen también por leyes de virtud, puesto que allí donde no llegan los medios de coacción sí lo hacen las intenciones de virtud, pero si el gobernante quiere conducir a los ciudadanos por la fuerza hacia esa comunidad, contradice la libertad que la anima, además de que mina y hace insegura la constitución política, porque usa su poder político de manera ilegítima y puede suscitar la respuesta de la ciudadanía, respuesta que puede quebrar la comunidad política. De esta manera, el ciudadano permanece enteramente libre respecto a si quiere o no ingresar a una comunidad ética.

La comunidad civil ética reposa sobre leyes públicas y contiene una constitución política. Quienes se ligan a ella han de tolerar las restricciones que sus leyes les imponen, puesto que no debe haber nadie en ella que esté en conflicto con el deber de los miembros como ciudadanos. El concepto de una comunidad ética está referido siempre a la totalidad de los hombres, porque los deberes de virtud conciernen a todos los hombres. No sucede lo mismo con la comunidad política, donde las leyes conciernen sólo a los ciudadanos del Estado y no a todos los hombres en general. En el Estado los hombres aún no forman una comunidad ética, y se encuentran en un estado de 
naturaleza ética. Es un imperativo moral que los seres humanos salgan del estado de naturaleza ética para hacerse miembros de una comunidad ética. Este imperativo no es un deber de los hombres para con los hombres, sino del género humano para consigo mismo. Esta unión ética del género humano en tanto ser racional se realiza en vistas a la consecución del Sumo Bien, entendido como Bien comunitario. Así, el Sumo Bien exige la unión de las personas en un todo en orden al mismo fin, a saber, un sistema de hombres bienaventurados. Se trata pues de la idea de una república universal según leyes de virtud.

En el texto de la Religión dentro de los límites de la mera razón Kant señala que "una comunidad ética solo puede pensarse como un pueblo bajo mandatos divinos, esto es: como un pueblo de Dios y ciertamente bajo leyes de virtud" (Kant, 2001, p. 125). Con esta idea, Kant realiza la conexión entre la comunidad ética y la doctrina de la virtud desarrollada en el texto de la Metafísica de las costumbres. La articulación de esta doctrina hunde sus raíces en la idea de dignidad desarrollada en la Fundamentación de la metafísica de las costumbres. Esta idea representa la segunda parte de la teoría moral kantiana y supone la exigencia de no considerar a la humanidad en la propia persona como en la persona de cualquier otro solo como un medio, sino al mismo tiempo como un fin en sí mismo. Así, en el mundo social, las personas deben tratarse como medios para el funcionamiento de las instituciones sociales y políticas, pero al mismo tiempo, deben ser considerados como fines en sí mismo. Considerarse a sí mismo y a cualquier otro como un fin en sí supone a) no utilizarlo solamente como medio, es decir, no instrumentalizar o manipular al otro, b) considerar que tanto uno mismo como el otro es una persona en tanto es capaz de darse fines a sí mismo, es decir, es capaz de organizar un proyecto de vida y, como consecuencia de ello, c) considerar al otro como a sí mismo como alguien que tiene derecho a la justificación¹.

A partir de estas consideraciones, que se encuentran capturadas por la idea de la dignidad de todo ser racional, Kant desarrolla, en la Metafísica de las costumbres, las ideas tanto de virtud como de deberes de virtud. Estas ideas resultan ser un despliegue del significado que tiene la dignidad para Kant. La virtud representa la fuerza para realizar lo que las leyes morales exigen. Kant define la virtud como "...la fuerza de la máxima del hombre en el cumplimiento de su deber" (Kant, 2005, p. 394) que se dirige a vencer los obstáculos que representan las inclinaciones naturales. Este combate de las inclinaciones se encuentra orientado a dos fines importantes, a saber, la propia perfección y la felicidad de los demás. Ambos fines denotan dos tipos de deberes de virtud de toda persona, a saber, a) el deber de la propia perfección, y b) el deber de comprometerse con la felicidad de los demás. De esto queda claro que la cuestión del perfeccionamiento del otro no es asunto mío y cuando considero que es mi deber perfeccionar al otro lo que estoy cometiendo es injusticia.

El primer deber de virtud, la propia perfección, consiste fundamentalmente en la perfección moral de la persona. Dicho perfeccionamiento incorpora la consecución de la felicidad, pero de un modo claramente especificado: se trata de hacerse digno de

1 Rainer Forst ha formulado, elaborado la interpretación de la segunda formulación del Imperativo Categórico como el derecho, que asiste a toda persona, a obtener justificación respecto de las normas. Cf. FORST, Rainer; The Rigth to Justificaton. Elements of a Constructivist Theory of Justice, Columbia University Press, 2014. 
la felicidad y de esperar obtenerla solo bajo dicha condición. El segundo deber, que se inscribe en la virtud, consiste en colaborar con la felicidad de los demás siempre que se utilicen medios morales y el tipo de felicidad que se busque para ellos sea compatible con la moral. Ambos deberes centrales de la virtud establecen una conexión claramente especificada entre la virtud y la felicidad. Esta relación coloca a la virtud como elemento prioritario y la felicidad como elemento subordinado. Además, la felicidad no está siendo pensada como consecución de la misma de manera directa, sino como la exigencia de hacerse digno de ella y como algo que no se realizara necesariamente, pero respecto de lo cual cabe albergar la esperanza de alcanzarla. Esto es lo que denomina Kant "Supremo Bien"2.

El deber de virtud para con uno mismo exige el combatir una serie de obstáculos naturales, entre los que se incluye la mentira, la avaricia y la falsa humildad, además de cultivar disposiciones morales y físicas. La disposición moral fundamental que la virtud manda cultivar es la del autoconocimiento moral, a saber "... penetrar hasta las profundidades del corazón más difíciles de sondear" (2005, p. 441). La disposición física fundamental es aumentar la perfección natural. Kant divide los deberes de virtud para con los demás de la siguiente manera: de una parte, se encuentran tanto el deber de amar a los otros hombres, que incluye en deber de beneficencia, como el deber de gratitud y el sentimiento de simpatía considerado como un deber. De otra parte, se encuentran los deberes de virtud hacia los otros hombres nacidos del respeto que se les debe.

De esta manera, los deberes para con otros suponen la idea de que cada persona es capaz de organizar su propio proyecto de vida buena. En este punto Kant toma distancia de la idea aristotélica de vida buena, así como de los proyectos desarrollistas que se han generado en Latinoamérica puestos en marcha durante la segunda mitad del siglo XX y del proyecto del neoliberalismo económico retomado y echado a andar con fuerza después de la caída del Muro de Berlín, proyecto que plantea sustituir el desarrollo de la sociedad por parte del Estado por el desarrollo del mercado globalizado por parte de los agentes económicos transnacionalizados.

Aristóteles concebía la vida buena como un proyecto asociado a la polis y definida por ella. De manera que sólo se puede realizar al interior de la polis, participando de sus instituciones, y realizando las virtudes definidas en ésta. En tal sentido, el bien no es un término cuyo significado podría definir de manera particular las personas, sino que se trata de un término asumido colectivamente por la comunidad (Tugendhat,1997, pp. 235$237)^{3}$. En contraposición, Kant sostiene que cada persona es capaz de definir por

2 En este punto, Kant se conecta con la tradición de la filosofía moral que proviene desde la antigüedad. La posición de Kant al respecto se abre paso en debate con las concepciones clásicas del Supremo Bien, en especial con la desarrollada por los estoicos y la presentada por los epicúreos, que representan dos puntos de vista antagónicos al respecto.

3 Lo que indica Tugendhat es que en el libro I capítulo 6 de su Ética a Nicómaco, Aristóteles señala que la investigación respecto de la verdadera felicidad humana debe abandonar el plano del debate de las concepciones en debate a centrarse en una noción de naturaleza humana cuyo despliegue pleno conduce a la felicidad. Puesto que la ética tiene como eje central la felicidad, las consideraciones respecto de las virtudes dependen de dicha naturaleza humana. Y si la política tiene como tarea los arreglos institucionales para que los ciudadanos realicen su felicidad, esto quiere decir que la política consiste en colocar una concepción de felicidad compartida para que los ciudadanos se ajusten a ellas porque ésta se deriva de la "naturaleza humana". Cf. ARISTÓTELES; Ética a Nicómaco, Madrid: Alianza Editorial, 2008. Libro I, capítulo 6. 
sí mismo su proyecto de vida buena, de tal manera que el deber de virtud que tenemos para con los demás consiste en colaborar con el otro en la realización su propio proyecto de vida, siempre que tanto el proyecto como los medios de colaboración sean dignos ${ }^{4}$.

En el caso de los proyectos desarrollista y el del neoliberalismo sucede que todos dejan entre paréntesis la autonomía de las personas e imponen un proyecto de vida que supuestamente expresa el desarrollo adecuado de las personas 5 .

La dignidad exige considerar a cada cual como un fin en sí y, por lo tanto, permitir que cada cual desarrolle su propio proyecto de vida. Esto se realiza de manera plena en el contexto de lo que Kant denomina "Verdadera Iglesia", es decir, aquella que asume los mandatos de la razón como si se tratase de mandatos divinos. Esta Iglesia se concreta en la comunidad ética, la cual representa el espacio en el cual las relaciones entre las personas pueden llegar a realizarse bajo la forma de relaciones de virtud. De esta manera, la idea de comunidad ética aparece como regulativa y cargada de potencial crítico, el que se manifiesta claramente en la comparación con las relaciones sociales fácticas en las cuales las personas son inscritas en relaciones y

4 Alguien podría suponer que esta idea kantiana se encuentra en el concepto de philia o amistad desarrollada por Aristóteles en la Ética a Nicómaco, donde se señala que los amigos se comprometen con la realización del bien del otro. Sin embargo, los contenidos de las virtudes fundamentales presentadas por Aristóteles se presentan como conceptualizado por la comunidad y no por el individuo, y Aristóteles asocia la eudaimopnía a la realización de las virtudes así determinadas.

5 El proyecto, propio del desarrollismo, de exigirle al otro que se proponga los fines que yo considero correcto ha tenido varias expresiones en propuestas políticas. considero correcto ha tenido varias expresiones en propuestas políticas. Todas estas propuestas tienen como objetivo eliminar la diversidad de fines que las personas pueden plantearse en la sociedad. Esta eliminación de la sociedad se puede buscar con buena voluntad o con objetivos de someter al otro. Las políticas desarrollistas llevadas a cabo en los años 70 estaban inspiradas en la creencia que desde el Estado se podía conducir a los ciudadanos hacia los fines correctos. Desde la caída del Muro de Berlín, se ha reactualizado esta actitud, pero esta vez no se plantean desde el Estado, sino desde agentes específicos de la sociedad. El proyecto neoliberal llevado adelante por los agentes dominantes en el mercado considera que saben cuáles son los fines que los ciudadanos deben plantearse como objetivos de vida. La arena social en la que se expresan con mayor claridad estos proyectos es la educación, porque esta es la que se figura como la que modela los anhelos de las personas bajo la formación de emprendedores. Todos estos proyectos, tanto en el ámbito interpersonal como en el social y político, se presentan señalando que se tiene un supuesto conocimiento metafísico, como la idea de naturaleza humana. Lo que es claro es que quien afirma conocer la naturaleza humana o la estructura metafísica del mundo o está confundido o está mintiendo. Es por ello que la actitud crítica que Kant desarrollo en su filosofía, es sumamente productiva para cuestionar los proyectos que amenazan la democracia

El proyecto neoliberal parte de una concepción metafísica del mundo, la sociedad y las personas. En nombre de ese supuesto conocimiento proceden a imponer un modelo de vida homogeneizarte. Dicha metafísica señala, entre otras cosas, que las personas son competitivas y libres por naturaleza. De esta manera, el libre mercado resulta ser la estructura social idónea para que ellas desarrollen su finalidad adecuadamente (de acuerdo a lo que los neoliberales consideran que es la finalidad de todo ser humano, es decir, ser emprendedor). Dicha finalidad es la de todo ser humano en general y la idea de libertad que se utiliza como punta de lanza de dicho proyecto tiene una extraña cualidad. El neoliberalismo supone que, si se deja a las personas elegir libremente, estas escogerán el modelo de vida que los neoliberales les plantean (y si no lo hicieren, se trataría de personas que están profundamente equivocadas por distorsiones mentales o ideológicas). Esta idea no debe sorprender, pues estos pensadores suponen tener un conocimiento tal de la naturaleza humana de la que se deduce que las personas en condiciones de libertad erigirán este y no otro proyecto. Lo mismo sucede con los defensores de un proyecto religioso de la sociedad o de los defensores del desarrollismo o los seguidores de Lenin. Todos ellos derivan un proyecto de vida y de sociedad homogénea partiendo de una concepción metafísica del mundo y de la idea de una imagen de vida buena. Tanto Sendero Luminoso como los activistas pro-vida creen conocer la naturaleza de las cosas. Lo mismo ha sucedido con los dos proyectos que se dieron la posta en América Latina, el desarrollismo y el neoliberalismo. 
en sistema de intercambio que terminan cosificándolas. En la contraposición entre el principio bueno y el principio malo que Kant presenta en su texto sobre religión se sintetizan dos tipos de intercambios que las personas realizan en el seno de la sociedad, a saber, intercambios cargados de potencial moral e intercambios desprovistos de dicho potencial. El primer tipo de intercambio son los de bienes morales como a) el de acciones cargadas de virtud, b) los dones y c) los intercambios recíprocos mercantiles cargados de potencial moral, es decir, que hacen valer la dignidad de las personas; en cambio, el segundo tipo es el de los intercambios mercantiles que terminan cosificando a las personas por medio de la dominación económica. Por intercambios recíprocos mercantiles cargados de potencial moral me refiero a los intercambios económicos que carecen de finalidad lucrativa y que consideran la dignidad de las personas en el mismo proceso de intercambio. En cambio, los intercambios al interior del mercado tienen como finalidad la ganancia. La ganancia económica incorpora en su propia dinámica el signo de la dominación, por lo cual es adversa a la dignificación de las personas ${ }^{6}$.

Hemos visto la manera en la que Kant presenta una eclesiología crítica bajo la idea de comunidad ética. A esta contrapone la idea de estado de naturaleza ético. La primera idea representa el orden eclesial perfecto, aquel que corresponde a la religión que es definida como el conjunto de leyes morales producidas por la razón entendidas como si fuesen mandatos divinos. En ese trasfondo ideal las personas no solo cumplen con las leyes morales racionales, sino que además se consideran a sí mismas como a otras como dignas, es decir, como fines en sí mismas. La idea de estado de naturaleza ética, en cambio, representa el estado infernal de un pueblo de demonios que no se encuentran dispuestos a seguir ley moral alguna ni relacionarse entre sí conforme a deberes de virtud. La idea de dignidad carece de valor y lo único que articula las relaciones entre las personas son las leyes de la naturaleza que son representadas por el autointerés y la exigencia moral rala de la autopreservación de la propia vida. En medio de estos dos polos ideales se desarrollan todas las relaciones propias de las iglesias estatutarias que combinan exigencias morales con reglas del autointerés establecidas por autoridades político-partidarias que fingen ser autoridades religiosas, es decir, morales, y que imponen su dominación de un supuesto conocimiento metafísico de Dios y de la naturaleza humana. Además, éstas articulan una serie de instituciones eclesiales que, si bien son imperfectas en sentido moral, no se hunden en el abismo del estado de naturaleza ético. En este espacio intermedio las personas se encuentran con las exigencias morales, así como con los deberes de virtud, pero sucede que las inclinaciones naturales en ellas hacen que su cumplimiento con estas exigencias y deberes se encuentre intercalado con el no cumplimiento. Esto caracteriza lo propio de las iglesias estatutarias y de las personas que las componen.

\section{El proyecto neoliberal}

Estas ideas respecto a la eclesiología permiten desarrollar una crítica de las relaciones sociales al interior de la sociedad civil. Ahora, la idea de comunidad

6 En este sentido, es necesario aislar el poder que se consigue a través de la acumulación económica del dinero de la forjación de poder político, a fin de consolidar procesos de democratización. Al respecto, Cf. TILLY, Charles; Democracia, Madrid: Akal, 2010. 
ética representa la idea de sociedad civil en tanto modelo, mientras que la idea de estado de naturaleza ético representa el colapso de toda configuración civil. En medio de estos polos ideales se encuentran las relaciones humanas fácticas entre personas al interior de las sociedades civiles operantes. En ellas se entrelazan relaciones morales enmarcadas por deberes de virtud inspirados en la idea de dignidad, con intercambios recíprocos de bienes, dotación de dones y relaciones mercantiles al interior del sistema del mercado. Esto hace que convivan al mismo tiempo relaciones morales con relaciones distorsionadas, a la vez que se abre la posibilidad de extraer de las relaciones distorsionantes del mercado relaciones cargadas de valor moral.

Con el propósito de ofrecernos una pista de investigación respecto de las relaciones económicas que se desarrollan en las sociedades contemporáneas, y para entender su dinámica y modificaciones, Karl Polanyi (2010) describió tanto dichas relaciones como el fenómeno que por el cual fueron confinadas al interior de mercado. Amparado en la investigación histórica, sociológica y antropológica que tuvo a su disposición logró explicar que la economía incluye un conjunto de elementos que incorporan intercambios recíprocos, ideas de índole moral y relaciones mercantiles. Estas intuiciones fueron reforzadas por los estudios desarrollados por la antropología económica (Mauss, 2009 Sahalins, 1983). Esta complejidad de las relaciones económicas tiene como objetivo comprender la dinámica de la teoría de los mercados autorregulados por medio de la idea de arraigo y los intentos fallidos de desarraigo llevados a cabo por los partidarios del neoliberalismo económico.

El concepto de arraigo expresa la idea según la cual a) la economía se entiende como intercambios recíprocos de bienes, flujo de reconocimiento moral e intercambio mercantil, a la vez que se encuentra b) empotrada en las sociedades concretas. El ascenso de las ideas neoliberales durante el siglo XIX, como producto de los cambios de la revolución industrial durante el siglo XVIII, produjo transformaciones tanto en la forma de entender la economía como en la relación entre la economía y la sociedad. La transformación central consistió en el paso de una economía dirigida a la subsistencia a una economía dirigida a la ganancia. De este cambio se derivaron una serie de otros cambios. Por un lado, la economía fue despojada de su complejidad y fue reducida a la red de mercados autorregulados. De otra parte, intentaron desarraigar la economía de la sociedad, produciendo un proceso de desintegración social. El camino que siguieron para tratar de llevar adelante este objetivo fue generar mercados perfectamente autorregulados, pero como el llevar a cabo este proyecto llevaría a la sociedad a un abismo, la misma sociedad, empezando por los mismos empresarios, no permiten que se concrete la consolidación de los mercados autorregulados, y tampoco se concrete el desarraigo de la economía respecto de la sociedad, en un proceso que Polanyi denominó "doble movimiento". Los mismos empresarios exigen que el Estado intervenga para poder resolver las dificultades de los mercados. Pero esta imposibilidad práctica de la consolidación de los mercados autorregulados es utilizada por los defensores del neoliberalismo como un acicate para su retórica ideológica. De llevarse a cabo el proyecto que tienen en ciernes, se conduciría a la sociedad en su conjunto al abismo, y, por eso la sociedad, empezando por los empresarios, dan marcha atrás; en cambio de señalar eso, lo que afirman es que la acción de agentes ideologizados y partidarios de la intervención del Estado, 
no permite la concreción del proyecto que defienden e impiden a la sociedad de los beneficios que supuestamente producirían los mercados completamente autorregulados, desarraigados de la sociedad y dominadores de la misma.

Al mismo tiempo, los impulsores del proyecto neoliberal, buscaron una manera de asegurar los mercados autorregulados nacionales a través de la forjación de una sociedad mundial de mercado. Para ello crearon el llamado "patrón oro", por medio del cual todos los Estados respaldarían sus monedas en el oro, de tal manera que, entre otras cosas, podrían tener un sistema de equivalencia de precios mundial y podrían regular la existencia de circulante a través de la cantidad de reservas en oro que tuviesen los bancos centrales nacionales. Esto permitió la transnacionalización de la inversión, del comercio y de los flujos financieros, de manera que ya no se encontraban sujetas a los mercados nacionales, sino que podían fluir por una sociedad de mercado mundial. Con ello, el esfuerzo fue desarraigar el mercado y consolidar la transformación de la sociedad en una sociedad de mercado. Lo característico de una sociedad de mercado es que, en vez de que el mercado se empotre en un contexto social, suceda lo contrario, a saber, la sociedad se encuentra gobernada por las relaciones de un mercado mundial autorregulado.

Pero, como este proceso conduce a la desintegración social, las sociedades europeas de fines del siglo XIX decidieron dar marcha atrás ante el abismo que veían venir. Así que los estados decidieron elevar los aranceles para proteger sus producciones locales y emprendieron una política neocolonial en África, con el objetivo de incrementar su mercado interno. Esto los condujo a una conflagración mundial (la Primera
Guerra Mundial) después de un siglo XIX prácticamente carente de eventos bélicos. Terminada la Primera Guerra, la consecución del proyecto neoliberal de constituir un mercado mundial autorregulado produjo la gran depresión del 29 y finalmente al ascenso del fascismo en la década de los 30. El fascismo representó una respuesta radical en contra del proyecto neoliberal, de tal magnitud que, a parir del 45 hasta el 89, se impusieron las ideas de Keynes y el orden mundial westfaliano-keynesiano, excepto en EE.UU. con Reagan e Inglaterra con Thatcher, donde se reactualizó el intento neoliberal de mercados autorregulados a partir de 1980.

Es necesario señalar que uno de los elementos que contribuye a consolidar el orden mundial westfaliano-keynesiano fue la Revolución Rusa de 1917. Dicha revolución no sólo modificó las relaciones económicas al interior de los países pertenecientes al bloque soviético, sino que su impacto se dejó sentir en el mundo entero. Europa occidental y Estados Unidos hicieron que las ideas de Keynes vencieran a las ideas de los defensores de los mercados autorregulados. Keynes defendía la idea de que, si bien no debería desecharse los mercados, era importante que los estados intervinieran para introducir regulaciones. Estas ideas tenían como objetivo evitar que las condiciones sociales sean propicias para que la prédica y la práctica de los partidos comunistas prosperen. De esta manera, la Revolución del 17 transforma en capitalismo en esos países (Negri, 2003). En el entonces llamado "tercer mundo", la forma en que impactó la Revolución de Octubre fue a través de la consolidación de gobiernos desarrollistas que decidieron generar las bases materiales del bienestar social desde el Estado. La gran mayoría de estos gobiernos fueron dictaduras, como el caso de Velasco en Perú o Nasser en Egipto. 
Las ideas de Keynes no fueron el único efecto que tuvo la Revolución Rusa al interior de la economía capitalista. El otro efecto fue lo que los marxistas estructuralistas franceses denominaron "El Fordismo". Este fenómeno despliega una idea que se encuentra en Marx, según la cual, una condición necesaria para que la economía capitalista pueda seguir funcionando es evitar la sobreproducción. La existencia de ella llevaría a declive el sistema capitalista debido a que el precio de los productos se viene abajo y haría quebrar a las empresas. Por ello es necesario que el mismo capitalismo pueda crear un mercado que pueda absorber la producción pagando el trabajo de los trabajadores de las fábricas de modo tal que ellos puedan comprar los bienes producidos por la economía capitalista. El Fordismo, junto con las ideas de Keynes se echaron a rodar en las sociedades capitalistas desde el fin de la Segunda Guerra Mundial hasta la caída del Muro de Berlín. De tal manera que, ambas cosas juntas, consolidaron el llamado "Estado de Bienestar" que subsistió en Europa hasta 1989 y en EE.UU. e Inglaterra hasta 1980.

A la caída del Muro de Berlín, el modelo keynesiano de sociedades de bienestar y de mercados parcialmente regulados por el Estado, cayó en desgracia y el neoliberalismo echó a rodar su proyecto de mercado mundial autorregulado y de sociedad de mercado mundial, a la vez que reemplazó el "Estado de bienestar" por el "Estado de inseguridad" (Frasser, 2008). Al mismo tiempo, en los países del antiguo "tercer mundo" fracasó el proyecto del Estado desarrollista. De este modo, el modelo de mercados autorregulados resulta siendo la expresión más significativa de lo que se entiende hoy en día como globalización y, más precisamente, globalización financiera. Pero, desde entonces, aquello que Polanyi denominó "doble movimiento" desapareció y se ha impuesto un movimiento unidireccional a nivel global, de manera tal que la escalada neoliberal parece no tener fuerzas externas de contención (Fraser, 2017). Pero la misma situación ha hecho surgir dos fenómenos globales importantes. De una parte, los Estados Unidos de América han visto debilitada la posibilidad de seguir sosteniendo su hegemonía sin competencia. El mundo global financierizado ha visto la emergencia de nuevas potencias, especialmente la China. Por otra parte, la llamada "Guerra Fría" se ha reactualizado a través de la configuración del eje Rusia, Irán y los países del ALBA, entre otros. A su vez, la emergencia de los movimientos pro modificación de las condiciones de la globalización (como el Foro Social Mundial), el fortalecimiento de una opinión pública transnacional muchas veces apoyada por las redes sociales, la aparición del terrorismo internacional y el terrorismo cibernético; todos estos fenómenos están complejizando el movimiento unilineal del proyecto de consolidación de un mercado mundial globalizado.

\section{La crítica al proyecto neoliberal}

Una de las cosas que la investigación de Polanyi y que la antropología económica reafirma es la riqueza de los procesos de intercambios económicos, que incorporan intercambios recíprocos de bienes e intercambios de bienes a través del mercado. Si conectamos este resultado con las ideas desarrolladas por Kant en sus trabajos sobre religión y sobre la virtud, podemos añadir que la sociedad no solo realiza intercambios económicos sino también es el espacio en el cual se realizan relaciones morales bajo la forma del cumplimiento de deberes de virtud. De esta manera, es posible extraer de estos trabajos una filosofía social crítica 
de las relaciones sociales existentes en la actualidad para incluir elementos normativos que permitan llevar adelante la crítica y evaluación de los proyectos sociales puestos a andar en el mundo contemporáneo.

Las claves centrales de la crítica social que se extrae de esta lectura de Polanyi a la luz de la idea de comunidad ética de Kant se centran especialmente en los siguientes puntos:

a) El proyecto del neoliberalismo de desarraigar los mercados de la sociedad trae consigo un movimiento complementario de someter a la sociedad bajo las reglas del mercado. Ello implica la desintegración de la sociedad, de tal manera que los intercambios recíprocos quedan marginados del análisis económico y marginados también de la práctica social. Esto acarrea que el empobrecimiento al que la población es arrojada reduce la capacidad que ésta tiene de intercambios recíprocos como dones, de tal manera que las personas no pueden sembrar las bases del reconocimiento moral que denominamos agradecimiento.

Junto con ello, la consolidación de un mercado mundial termina por establecer relaciones de desigualdad entre regiones, como el caso de norte y sur. Las relaciones económicas dentro de un mercado mundial generan relaciones de intercambio económico mercantil que somete a unos a la dominación de otros, a la vez que los capitales transnacionalizados no sólo generan hegemonía y colonealidad en las periferias del orden mundial, sino también turbación en el mismo centro, pues el capital deslocalizado, busca expandir sus ganancias trasladando departamentos empresariales enteros de un continente a otro, con lo cual deja en la calle a los mismos mercados nacionales del centro del mundo globalizado, especialmente en los momentos de crisis económica como la desatada a partir del 2008. Al mismo tiempo, empuja a personas nacidas en la periferia a migrar, tanto de manera legal como ilegal, a los centros para poder acumular dinero y enviar remesas a los suyos, a cambio de lo cual reciben reconocimiento, prestigio y agradecimiento.

b) Al someter la sociedad al mercado, el proyecto neoliberal convierte el trabajo en una mercancía y a las personas como engranajes del sistema. De tal manera, la dignidad de las personas termina siendo profundamente erosionada, pues se daña el tejido social en el que las relaciones sociales hacen brillar la dignidad de las personas.

Junto a esto, la economía da un vuelco inédito en la historia económica de la humanidad: convierte al trabajo, al terreno y al dinero en mercancías. El mercado de trabajo termina por convertir a la persona en una mercancía cuyo precio se encuentra regulado por las leyes del mercado en general. De esta manera, una serie de relaciones sociales se desfiguran y pierden el valor moral que la dignidad humana les otorga.

La parcelación y transacción económica del territorio se convierte en una exigencia para el mercado globalizado. Esto se debe a que es del territorio de donde el mercado extrae la materia prima para recrearse permanentemente. En un primer momento, la parcelación del territorio tuvo como objetivo la posibilidad de ser comprada por el capitalista agroindustrial para la siembra de algodón y el cultivo de pastizales que permitiesen criar ganado lanero, todo ello para abastecer de materias primas 
a las nacientes industrias textiles en Inglaterra durante los siglos XVIII y XIX. Ya, en el siglo XX y en el siglo XXI, la expropiación del terreno a las comunidades tiene como objetivo la extracción de minerales, de petróleo y de gas que revitalizan desde las canteras formales, semiformales e informales. Y la del cultivo de coca, opio y marihuana lo hacen desde el lado delictivo.

La parcelación del territorio trae consigo gran conflictividad social en que se enfrentan, de una parte, el gran capital y, de otra, las comunidades nativas, los colonos y los ciudadanos que se ven despojados de sus territorios. Pero, a pesar de los tratados y convenios internacionales, especialmente el convenio 169 de la Organización Internacional del Trabajo (OIT) ${ }^{7}$, los gobiernos nacionales se colocan del lado del gran capital en contra de los pobladores debido a que tales gobiernos y estados han sido copados por los agentes del capital local que busca, de esa manera, poder entablar negocios con el capital transnacional. El hecho de que los gobiernos y los estados den la espalda a la sociedad para ponerse al servicio de los capitales transnacionalizados constituye una fuente profunda de corrupción de los estados.

La conversión del dinero en mercancía genera lo que se conoce como capital especulativo, el cual se expresa en el crédito y la especulación financiera en las bolsas locales e internacionales. La exacerbación del capital especulativo termina por generar crisis financiera, como la del 2008, que exige que los Estados protejan a los bancos y desprotejan a las personas que tienen sus casas hipotecadas.

c) En ese mismo movimiento, el proyecto del neoliberalismo termina por imponer un proyecto de vida y la homogeneización de los proyectos de vida, de tal manera que la persona no es considerada como un fin en sí y con la posibilidad de darse fines a sí misma. Todo lo contrario, el mercado le impone un proyecto de vida en nombre de una idea metafísica de la realización humana general que indica que el ser humano es un ser racional que buscará maximizar sus ganancias y elegirá las reglas del mercado como las mejores reglas posibles. Desde esta perspectivas, Nelson Mandela, Gustavo Gutiérrez y Teresa de Calcuta serían catalogados como agentes estúpidos debido a que no actúan como agentes racionales, es decir, no procuran maximizar sus ganancias en el mercado.

Sin embargo, a pesar de que las relaciones sociales se encuentran dominadas por estas relaciones, es posible rastrear elementos que permitan establecer una conexión entre las relaciones sociales con la idea de comunidad ética. Ello es posible dando dos pasos fundamentales: a) reintegrando en las relaciones sociales aquellos elementos que el giro mercantilista dejó fuera de la economía, y b) insertando una traición de carácter moral a los flujos del mercado.

Los trabajos de Polanyi, elaborados sobre la base de la antropología económica, especialmente a partir de los trabajos de Mauss y Sahlins, señalan que las relaciones económicas en las sociedades

7 Se puede revisar el convenio 169 de la OIT en http://www.ilo.org/wcmsp5/groups/public/_--ed_norm/_ normes/documents/publication/wcms_100910.pdf. 
previas a la revolución industrial incluían intercambio de dones y prestigio social, junto a intercambios recíprocos e intercambios en el mercado (a través del trueque o el dinero). Incluso, no en todas las sociedades, se formó una institución como aquella que conocemos como mercado, en el sentido de una institución en la que las personas intercambian visà-vis unos bienes por otros en el mismo acto, ya sea a través del trueque o a través del dinero. De modo que lo que estas investigaciones antropológicas arrojan es que en las relaciones económicas el mercado no era la institución central y dominante, sino que éste se incorporaba en una gama de relaciones más amplia que incluía dones, dotación de prestigio y agradecimiento moral e intercambios recíprocos.

Con la revolución industrial, durante el siglo XVIII, y el desplazamiento del mercado hacia el centro de las relaciones económicas, los demás elementos comenzaron a ser marginales para terminar por ser expulsados de las relaciones económicas. Luego, mediante los esfuerzos por consolidar el proyecto neoliberal de desarraigar el mercado de la sociedad y subordinar la segunda a los mandatos del primero, los elementos que pertenecían a las relaciones económicas, como los dones, el prestigio social y los intercambios recíprocos terminaron por ser expulsados de las relaciones económicas, sino colocados tras las cuerdas en el campo de las relaciones sociales en general. Sin embargo, no desaparecieron y constituyen elementos marcados por un signo de gratuidad que interpela desde la moral a los intercambios meramente mercantiles. Dicha interpelación se produce de esta manera. Los intercambios mercantiles no sólo tratan de expulsar otro tipo de intercambios dentro de la sociedad, sino que por encontrarse asociados a la acumulación de capital establecen relaciones de dominación al interior de la sociedad. Las relaciones en el mercado tienden a producir lo que Michael Walzer denomina tiranía (Fraser, 1993). La tiranía, para Walzer consiste en el monopolio de un bien predominante. Un bien predominante es aquél que controla la distribución de los demás bienes de la sociedad. En el mercado sucede que el gran capital tiende a incrementar su posesión del bien predominante, que es el dinero, de tal manera que intenta tener el monopolio de éste produciendo, de esta manera, relaciones de dominación de unas personas sobre otras. Sin embargo, desde la posición marginal a la que han sido relegadas, los dones, el prestigio y los intercambios recíprocos iluminan, con una luz crítica, las relaciones económicas en general y las relaciones de mercado en particular al interior de la sociedad burguesa globalizada contemporánea. Estos últimos no establecen relaciones de dominación y tampoco tienden a la tiranía, sino que, más bien, expresan relaciones de reciprocidad, asimetría y libertad entre las personas al interior de la sociedad contemporánea. Por contener ese significado, cuestionan, desde donde se encuentran, a las relaciones mercantiles.

El aporte de la antropología económica nos ha ofrecido una imagen poco habitual de las relaciones económicas. Desde esta perspectiva, dichas relaciones incluyen entrega de dones, intercambios recíprocos, que son diferentes a los realizados en el mercado, e intercambios de bienes realizados a través del mercado, ya sea a través del trueque o mediados por el dinero. Los intercambios recíprocos suponen dar y recibir bienes diferentes que son considerados del mismo valor. Tales intercambios no suponen que la ida y vuelta de bienes se dan al mismo tiempo, sino que, por el contexto ritual o de otra clase, se encuentran el dar y recibir separados por el tiempo, y no 
necesariamente se trata de las mismas personas las que se colocan de la otra parte de la reciprocidad, tal como lo explica Mauss en su Ensayo sobre el don. Las ideas rituales, religiosas o de otro tipo fortalecen la confianza del recibir como contraparte del dar. Y dicha confianza fortalece la integración social. La lógica del don, en el sentido que tienen las remesas de dinero en la sociedad global contemporánea, supone el dar bienes y el recibir agradecimiento y reconocimiento de parte de quienes reciben. No hay ida y vuelta de bienes materiales, sino el reconocimiento moral aparece como contraparte. Tanto los intercambios recíprocos como el don incluyen la idea de que el intercambio mismo no se encuentra ligado a la aspiración de la ganancia y la acumulación económica, y por lo tanto no se encuentran bajo la lógica de la dominación entre personas. El don, entendido en este sentido, incluye un significado moral adicional debido a que quien dona lo hace por una motivación moral de ayudar a la otra persona y colaborar en salir de su dificultad. Por su parte, quien recibe el don otorga a la otra persona reconocimiento moral bajo la forma de agradecimiento.

Las relaciones de mercado se encuentran, en principio, desprovistas de ambos componentes morales debido a que ellas se desarrollan con el fin de la acumulación de riqueza por medio de la ganancia. El otro de la relación es alguien despersonalizado (puedo intercambiar bienes con cualquiera indistintamente) y el mismo intercambio produce asimetría por medio de la acumulación del capital, de manera que quien ha acumulado más capital tiene una posición de dominio dentro de las relaciones económicas asimétricas $^{8}$. De este modo, las personas se encuentran en posiciones diferentes

8 Resulta ser una mera idealización y, a la vez, una herramienta conceptual de justificación de los mercados autorregulados, la creencia que las partes en el mercado parten a la carrera que representa que la competencia económica en el mercado con las mismas condiciones. Ese presupuesto tiene dos problemas resaltantes, entre otros. En primer lugar, no es contrastable empíricamente, ya que las personas en las sociedades parten dotadas de condiciones desiguales para la competencia en el mercado, por ejemplo, algunos parten con más riqueza que otros, a la vez que hay personas que se insertan en el mercado cargando sobre sus espaldas una miseria económica galopante. Además, esta creencia ideológica lleva una comprensión de la pobreza en el mundo ajena a la explicación que señala que la pobreza tiene causas sociales en la mayoría de los casos. A contrapelo de esta explicación, esta concepción neoliberal suele sostener que la pobreza tiene su causa en la pereza de la gente o en la mala suerte de vivir en Estados fallidos. Cornel West y Tavis Smiley ha cuestionado en el 2012 la tesis según la cual la pobreza de las personas tiene su raíz en la pereza en The Rich and the Rest of Us. A Poverty Manifesto. Por otro lado, John Rawls ha sostenido en su Derecho de gentes que la pobreza de las personas que viven en estados fallidos o "lastrados por la pobreza" no tiene relación con las relaciones económicas en un mundo globalizado. La posición de Rawls al respecto se funda en su defensa de la posición estatista en el debate contemporáneo entre estatistas y globalistas (como Thomas Pogge, entre otros), debate que actualmente se ha complejizado con la incorporación de la posición de los transnacionalistas como Forst y Fraser, entre otros.

Pero más allá de este último debate, lo que importante es señalar que los presupuestos de los defensores del proyecto del neoliberalismo económico están partiendo de presupuestos altamente cuestionables para derivar sus posiciones sobre el supuesto potencial de generar igualdad socioeconómica de los mercados autorregulados y respecto de las causas de la pobreza en el mundo. Es más, ellos defienden la idea de que la causa de las desigualdades en el mercado es la intervención Estado en el mercado, ya sea porque el Estado es corrupto por naturaleza, ya sea porque los participantes en el mercado no son corruptos y se limitan a perseguir un fin supuestamente legítimo desde el punto de vista moral, a saber, la ganancia económica. Pero este último argumento presupone demasiadas cosas que hay que comenzar con examinar si son ciertos. ¿La intervención del Estado en los mercados necesariamente son fuente de corrupción?, ¿̇los agentes económicos privados son realmente irreprochables en cuanto a malas prácticas?, ¿es realmente la acumulación de riqueza, sin ninguna otra consideración, válida moralmente por sí misma?, ¿Los casos de comportamiento ético de empresas como Enrom representan casos aislados y marginales o son una alerta respecto de la corrupción de las empresas privadas? 
en el intercambio dependiendo de cuanto capital hayan acumulado. De esta manera, se producen relaciones de dominación, las cuales se acrecientan cuando las personas son convertidas en mercancías al ser entendidas como fuerza de trabajo cuyo valor se determina en dinero a través de ley de la oferta y la demanda. Además, la lógica de mercado, al convertir a las personas en fuerza de trabajo, en consumidores y en emprendedores, termina por desintegrar las relaciones sociales que necesitan que las personas sean reconocidas en su valor moral y en sus identidades particulares. La marea de la homogeneización es percibida por las mismas personas como una amenaza tanto para el valor moral de las personas, como para el funcionamiento de la sociedad.

\section{Las traiciones al mercado}

De esta manera, en el contexto en el que se está intentando llevar a cabo el proyecto de una sociedad de mercado autorregulado mundial (que se encuentra expresado en el signo económico de lo que conocemos hoy en día como globalización), no solo sucede que los mismos empresarios exigen que los estados intervengan en ciertos aspectos de la economía y en momentos determinados, lo cual constituye una traición al proyecto del mercado autorregulado mundial. Sin embargo, desde la caída del Muro de Berlín, la reacción de los empresarios y de los estados ha sufrido una debilitación frente a las coerciones del mercado autorregulado global, de manera que el escenario en el que nos enfrentamos hoy difiere en ese punto a lo que percibía Polanyi en su tiempo. Pero junto a esto, se abre la puerta a dos traiciones de carga moral.

La primera traición está representada por la emergencia del don desde dentro de las mismas relaciones de mercado. Aquí el fenómeno del don difiere de lo estudiado por Mauss en su ensayo, y se acerca más a regalos o remesas que no esperan retribución material, sino que demandan agradecimiento y respeto. Las personas, insertas en relaciones mercantiles utilizan los mismos bienes materiales para desconectarlos de los flujos mercantiles y conectarlos a otra red de intercambio convirtiéndolos en regalos, en remesas desde el extranjero, etc. Para realizar esta traición utilizan los mismos canales que el mercado ha establecido. Desde luego, el mercado ha establecido dichos mecanismos con fines completamente diferentes, fines que se encuentran subordinados a los intercambios mercantiles. Las personas traicionan dichos mecanismos y circuitos para hacer valer su condición de sujetos morales y la de los demás. A cambio de tales donaciones las personas reciben de sus beneficiarios valoración moral que se expresa a través del reconocimiento basado en el agradecimiento. Pero, también es posible que esta contraparte de la relación que el don inaugura no se realice y se produzca el tipo de fraude que denominamos desagradecimiento. En esto consiste la segunda traición de carácter moral: los beneficiarios no retribuyen con agradecimiento, y más bien les dan la espalda en diferentes sentidos morales.

Un tipo de relación particular es relevante como contrapunto en este momento de la dinámica moral de los intercambios. Se trata de la institución jurídica de la herencia. Ésta es, en sentido estricto, una dotación de bienes bajo la forma de don, pero el mercado ha vuelto equívoco de tal manera que ha sido desconectado de las relaciones morales para ser colocado en las relaciones mercantiles para incrementar la capacidad de dominación. La historia de dicha institución señala que al principio la herencia tenía una función social 
específica: garantizar que las uniones matrimoniales se realizaran entre las personas del grupo a fin de que los bienes no se dispersen. Pero con la dominación del mercado sobre la sociedad, la herencia se convierte en una dotación para que ciertos individuos puedan tener mayores posibilidades de negociación y dominio en el mercado. De esta manera, un tipo de donación es absorbida completamente por la lógica del mercado, a menos de que las personas decidan desviar la herencia a instituciones benéficas, educativas, etc., o a personas menesterosas.

Pero el derecho no sólo interviene en las relaciones de intercambio en el caso de la herencia, sino que se encuentra para ejercer fuerza coercitiva para fortalecer las relaciones mercantiles. El derecho privado protege las relaciones mercantiles a través del apoyo de la fuerza pública. De esta manera protege a los concurrentes de los fraudes que puedan producirse en las relaciones mercantiles. El mismo sistema de mercado se convierte en un sistema de coerción que regula la conducta de las personas en la sociedad. Pero las exigencias morales que brotan de la dignidad de las personas levantan un tercer sistema normativo que al lado de los otros dos sistemas normativos complejiza las relaciones de las personas dentro de la sociedad contemporánea dominada por el mercado mundial en tiempos de globalización. Pero, además, sucede que la fuerza coercitiva del mercado globalizado presiona sobre el derecho positivo para que se modifique a su favor y lo utiliza para potenciar su poder de dominación sobre la sociedad, de manera que la fuerza de los imperativos morales que brotan de la dignidad se encuentra debilitada.

De los mismos flujos en el mercado brota la fuerza moral para dotar de un sentido diferente a las mercancías.
Transformados en dones, los bienes son sustraídos de la telaraña de los intercambios mercantiles y son dotados de contenido moral. De este modo, los intercambios se insertan en el espacio social intermedio existente entre dos polos ideales. El primero lo constituye el polo de la idea de comunidad ética, mientras que el segundo se encuentra representado por el polo de la idea de estado de naturaleza ético. Mientras que la comunidad ética representa la perspectiva ideal de un mundo caracterizado solamente por intercambios recíprocos, el estado de naturaleza ético representa la perspectiva ideal de un mundo caracterizado solamente por relaciones de mercado. De esta manera, la comunidad ética sería un mundo de intercambios donde la reciprocidad sería plena y las personas serían tratadas como libres e iguales. En cambio, el estado de naturaleza ético sería el mundo de las relaciones de mercado sin paliativos en el cual las personas estarían sujetas a merced de la dominación del capital y no gozarían de libertad ni serían consideradas como iguales. Aquí la dominación llegaría a tal punto de penetración que las personas dejarían de ser consideradas como dignas y serían transformadas en mercancías.

Los dones y los intercambios recíprocos representan un camino, desde dentro del mercado, para transitar por el espacio intermedio que se abre entre la comunidad ética y el estado de naturaleza ético, tomando ambos elementos de la manera en que los acabamos de definir. De no existir esas traiciones al mercado, las relaciones del mercado se acercarían al estado civil ético. En cambio, gracias a la presencia de los dones y los fenómenos afines, el conjunto de relaciones que se realizan en el mercado se eleva de ese nivel primario, en el cual se desarrollan exclusivamente relaciones de dominación. 
De este modo se puede ver cómo teniendo como punto de vista crítico las ideas de comunidad ética y de estado de naturaleza ético, es posible percibir cómo se instala una tensión dialéctica en el seno de la sociedad civil mundial contemporánea en un mundo en condiciones de globalización, entre la moral y la dominación.

\section{REFERENCIAS}

ARISTÓTELES; Ética a Nicómaco, Madrid: Alianza Editorial, 2008.

FRASER, Nancy; Escalas de justicia, Barcelona: Herder, 2008.

FRASER, Nancy; El destino de la igualdad en un mundo financiero. Conferencia dada en la Universidad Diego Portales https://www.youtube. com/watch?v=3j8drI8lOd0. Visita I $4 / 2 / 2017$

FORST, Rainer; The Rigth to Justificaton. Elements of a Constructivist Theory of Justice, Columbia University Press, 2014.

KANT, Immanuel; La religión dentro de los límites de la mera razón, Madrid: Alianza Editorial, 2001.

-; La paz perpetua. Un esbozo filosófico, 1999.

- ; Fundamentación para la metafísica de las costumbres, Madrid: Alianza Editorial, 1012 .
-; Metafísica de las costumbres, Madrid: Tecnos, 2005.

MAUSS, Marcel; Ensayo sobre el don: forma y función del intercambio en las sociedades arcaicas, Bnos. As.: Katz, 2009.

NEGRI, Antonio; Crisis de la política: escritos sobre Marx, Keynes, las crisis capitalistas y las nuevas subjetividades, Bnos. As.: El cielo por asalto, 2003.

NN.UU.; Convenio 169 de la OIT en http://www.ilo.org/wcmsp5/

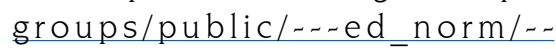
-normes/documents/publication/ wcms_100910.pdf.

POLANYI, Karl; La gran transformación, México: FCE, 2010.

SAHLINS, Marshall; Economía de la edad de piedra, Madrid: Akal, 1983.

TILLY, Charles; Democracia, Madrid: Akal, 2010.

TUGENDHAT; Ernst; Lecciones de ética, Barcelona: Gedisa, 1997.

WALZER, Michael; Las esferas de la justicia. Una defensa del pluralismo y la igualdad, México: FCE, 1993. 
